P60 (continued)

Conclusions and Implications: An independent study course can be an effective and feasible method to engage students in research. This approach to teaching and learning maximized research experience for a large team of students, while efficiently completing the data collection phase of a longitudinal study.

Funding: NIH.

\section{P61 Engaging Underrepresented Minority Students in Experiential Learning Opportunities and Research Training Through the "Abriendo Caminos" Program}

Anna-Sigrid Keck, PhD, akeck@illinois.edu, University of Illinois, Urbana-Champaign, 905 S Goodwin Avenue, Bevier Hall 122C, Urbana, IL 61801; Norma Gonzalez, DSc, MFA; Margarita Teran-Garcia, PhD, $M D$

Objective: To train future underrepresented minority (URM) professionals to work and meet the specific needs of underserved populations.

Target Audience: Higher education advisors, postgraduate mentors, and interested URMs.

Theory, Prior Research, Rationale: There is a need to develop a successful pipeline for URM's, increase retention to complete a bachelor's degree and recruitment for postgraduate education.

Description: Deliver a new year-long undergraduate curriculum that involves implementation of the communitybased research study Abriendo Caminos and provides experiential learning to URM students. This allows graduates and undergraduates hands-on training while participating in faculty-mentored research.

Evaluation: During its first 3 years, 54 undergraduates have participated in the program. Most of the students are first generation to attend college $(n=41)$, Hispanic/ Latino $(n=42)$ or African-Americans $(n=2)$. The curricula ( $\mathrm{n}=30$ undergraduates) has been rated $4.4-4.8$ of 5 . Other undergraduates $(n=24)$ have volunteered, participated in independent study, or been visiting scholars. Undergraduate posters $(n=21)$ and oral presentations $(n=2)$ have resulted in awards ( $\mathrm{n}=5$; three were Trio/McNair awards). To date, five have obtained a bachelor degree and 18 are planning to attend or have started graduate or medical school. Eight graduate students have participated in research and teaching with majority being Hispanic $(n=6)$ and two being Hispanic and first generation. Three have graduated, all Hispanic; two have accepted tenure-track positions and the third a post-doc. They have presented 37 posters and 14 oral presentations at 21 different conferences. Overall, they have gotten 38 awards, 23 research funds, and published 12 articles.

Conclusions and Implications: Abriendo Caminos demonstrates academic excellence among our URM students. The program prepares students to do research, service in underserved populations with increased cultural competencies, and to be competitive applicants for research opportunities. It also develops a supportive network system with levels of direct mentorship (peers, staff, and instructors) that are complementary and facilitates retention for successful terminal degrees.

Funding: USDA.

\section{P62 Environmental Nutrition: A Master's Degree Program Designed to be Relevant and Student-Responsive}

Robin Roach, EdD, MPH, RDN, rroach@memphis.edu, University of Memphis, School of Health Studies, Fieldhouse 161, Memphis, TN 38152

Objective: To develop and deliver a Master's Degree program in Environmental Nutrition at the University of Memphis that is relevant and student-responsive.

Target Audience: Health care professionals, science/ health educators, employees or those who desire employment within work settings with food and nutrition missions.

Theory, Prior Research, Rationale: The need to understand relationships between food systems and the environment is no longer considered a fleeting trend, but recognized as an essential link to the health and wellness of humans and of the earth. Graduate programs that address these relationships should be guided by relevant and theoretical foundations towards best practices. The challenge becomes developing and delivering these programs while remaining responsive to the shifting needs of our student populations. Several student-responsive strategies that have been reported as effective include asynchronous online delivery of content, allowing for focused experiences within the student's community, and creating pathways that value prior student experiences.

Description: A Master of Science (M.S.) Degree Program in Environmental Nutrition was developed and implemented at the University of Memphis in 2014. The 33credit hour, asynchronous-delivered online curriculum includes project and internship applications. Experiential learning credit is available.

Evaluation: Thirty-two students have enrolled in the program. Seventy-five percent $(n=24)$ are enrolled parttime. Curriculum content, online delivery, internship and project locations, and experiential credit options are reported as program strengths by $95 \%(n=30)$ of the students. Six students have graduated with four students scheduled to graduate this semester. Graduates and current students live in seven different states and include an organic farmer, wellness educator, extension agents, rancher, athlete, nurse, gardener, food service managers, dietetic technician, registered dietitian nutritionists, and non-profit employees.

Conclusions and Implications: The M.S. Program in Environmental Nutrition was successfully developed and is currently delivered. Positive program evaluations support the relevant curriculum, and online delivery, project and internship opportunities, and experiential credit as studentresponsive program strengths.

Funding: None. 